\title{
Improved Electrochemical Performance of NCM Cathode Materials Based on the Modification of the Salt Content in the Electrolyte
}

ORTIZ, M.; ČECH, O.; SEDLAŘíKOVÁ, M.

ECS Transactions

2019, vol. 95, iss. 1, pp. 3-8

ISBN 9781605603124

ISSN (Online): 1938-6737

DOI: https://doi.org/10.1149/09501.0003ecst

Accepted manucript

Final version: https://iopscience.iop.org/article/10.1149/09501.0003ecst 


\title{
Improved Electrochemical Performance of NCM Cathode Materials Based on the Modification of the Salt Content in the Electrolyte
}

\author{
M. G. Ortiz ${ }^{\mathrm{a}, \mathrm{b}, \mathrm{c}}$, O. Čech ${ }^{\mathrm{c}}$, and M. Sedlaříkovác \\ a Instituto de Investigaciones Fisicoquímicas Teóricas y Aplicadas (INIFTA), Facultad de \\ Ciencias Exactas, UNLP, CCT La Plata-CONICET, 1900, La Plata, Argentina \\ ${ }^{\mathrm{b}}$ Centro de Investigación y Desarrollo en Ciencia y Tecnología de Materiales (CITEMA), \\ Universidad Tecnológica Nacional - CICPBA, 60 y 124, 1923, Berisso, Argentina \\ ${ }^{c}$ Department of Electrical and Electronic Technology, Faculty of Electrical Engineering \\ and Communication, Brno University of Technology, Technická 10, 61600, Brno, Czech \\ Republic
}

In this work, NCM cathode materials, for Li-ion batteries, were synthesized via a solid-state reaction routine, in which manganese (IV) dioxide, nickel (II) oxide, cobalt (II) hydroxide and lithium hydroxide monohydrate were employed as metal precursors with different calcination temperature. The prepared materials were used as a cathode material for lithium-ion batteries and the electrochemical performance was studied by galvanostatic chargedischarge cycling, cyclic voltammetry, electrochemical impedance spectroscopy and rate capability, in which as electrolyte, $1 \mathrm{M}$ and $1.5 \mathrm{M} \mathrm{LiPF}_{6}$ in a mixture of ethylene carbonate and dimethyl carbonate (EC:DMC- 1:1 w/w and 1:2 w/w, respectively) were employed.

\section{Introduction}

Lithium-ion batteries (LIBs) with enhanced energy density are now pursued as the most viable power sources for portable electronics, electric and hybrid vehicles, and even for grid-scale power storage applications (1-2). The current LIBs technology is based on insertion-reaction electrodes and organic liquid electrolytes. With an aim to increase the energy density or optimize the other performance parameters, new electrode materials (34) and electrolytes (5-6) are being intensively pursued.

The development of new electrode materials with a high capacity and high level of safety is indispensable for high performance lithium-ion batteries but, at the same time, the other components of the system, such us the electrolyte, must be able to give a good response to these improvements. For the intercalation based cathode materials, within the three existing choices (chalcogenides, transition metal oxides and polyanion compounds) the most of research is focused on transition metal oxides due to their higher operating voltage and the resulting higher energy storage capability. Within these materials, the layered $\mathrm{LiMO}_{2}(\mathrm{M}=\mathrm{Mn}, \mathrm{Co}$, and $\mathrm{Ni}$ denoted as $\mathrm{NCM})$, have been extensively studied and considered to be a promising candidate of cathode material for future LIBs because of their high theoretical capacity, low cost, safety, high cycling stability and low toxicity (7-9). However, it is considered that the need to continue with these studies, to be able to improve their electrochemical behavior (especially with respect to its low initial coulomb 
efficiency and poor rate capability (7), is still present. To reach this goal, various strategies including optimized particle morphology (10), size (10), and composition (11), using the cation doping in the bulk phase (12), and surface coating (13) have been developed.

We propose a modification of the salt content concentration to overcome the disadvantages described in these systems. Thereby studies, including X-ray diffraction, cyclic voltammetry, cycling and electrochemical impedance spectroscopy for two concentrations of salt in electrolyte $(1 \mathrm{M}$ and $1.5 \mathrm{M})$ are presented in this paper.

\section{Experimental}

The NCM materials were synthesized through a solid state reaction routine. The precursor powders were prepared via a ball milling. In a typical process, raw materials employed in the experiment were nickel oxide (99.8\%), cobalt hydroxide (95\%), manganese oxide (95\%) and lithium hydroxide monohydrate $(98.9 \%)$. All the starting raw materials, with the certain molar ratio $\mathrm{Li}: \mathrm{Ni}: \mathrm{Co}: \mathrm{Mn}=1: 0.33: 0.33: 0.33$, were milled for $1 \mathrm{~h}$. Afterwards, the mixture was heated in two temperature steps, first at 450 ${ }^{\circ} \mathrm{C}$ for $5 \mathrm{~h}$ and then, at different temperatures $\left(800 / 850 / 900 / 950{ }^{\circ} \mathrm{C}\right)$ for $12 \mathrm{~h}$.

The crystal structure of the samples was characterized by powder X-ray diffraction (XRD) measurements were performed on Rigaku Miniflex 600 powder diffractometer ( $\mathrm{Cu}$ Ka radiation, $40 \mathrm{kV} 15 \mathrm{~mA}$ ) with a D/Tex Ultra 250 1D CCD detector, in the $2 \theta$ range of $10-100^{\circ}$ to depict the peak assignment for the phase present.

For the electrochemical tests, the working electrodes were prepared by casting the slurry of the active material (NCM-800/850/900/950) (80\%), Super P (10\%) and polyvinylidene fluoride (PVDF) (10\%) dissolved in the appropriate amount N-methyl-2pyrrolidone (NMP) on an aluminum foil. Electrochemical experiments were carried out with the cell ECC-STD (El-CellC), which were assembled inside an Ar-filled glove box, using the prepared working electrodes as cathode and Li metal foil as counter as well as reference electrodes. As electrolyte, $1 \mathrm{M}$ and $1.5 \mathrm{M} \mathrm{LiPF}_{6}$ in a mixture of ethylene carbonate and dimethyl carbonate (EC:DMC- 1:1 w/w and 1:2 w/w, respectively) was employed.

Cyclic voltammetry was done in the potential window from 2 to $4.9 \mathrm{~V}$ vs. $\mathrm{Li} / \mathrm{Li}^{+}$and the scan rate was set to $0.1 \mathrm{mVs}^{-1}$. The cells were cycled in the potential range $2-4.8 \mathrm{~V}$ vs. $\mathrm{Li} / \mathrm{Li}^{+}$, using a VMP-2Z multi-channel galvonostat-potentiostat (Bio-Logic). Electrochemical impedance spectroscopy (EIS) measurements were performed using similar equipment with an $\mathrm{AC}$ voltage amplitude of $5 \mathrm{mV}$ in the frequency range of 0.1 100.000 Hz. All electrochemical tests were performed at room temperature.

\section{Results and Discussion}

The structural information of samples was studied by XRD measurement, and the diffractograms are presented in the Fig. 1. The main diffraction peaks are well indexed to a typical $\alpha-\mathrm{NaFeO} 2$ structure of the R-3m space group. Additionally, no impurities were 
observed in the structures. The clear split between the 006/012 and 108/110 and peaks points out that the materials have good hexagonal structure (14-15). Lattice parameters and relative peak intensities were estimated from XRD and the results were listed in Table 1. The high value of c/a (> 4.899) and the low ratio of R (I (006)+I (102))/I (101)) indicated good layered structure and hexagonal ordering, respectively (16).

As listed in Table 1, the c/a and R of the NCM-850 were better than those of NCM$800 / 900 / 950$ sample, which indicated that the NCM-850 sample exhibited better structure stability and therefore good electrochemical performance was expectable.
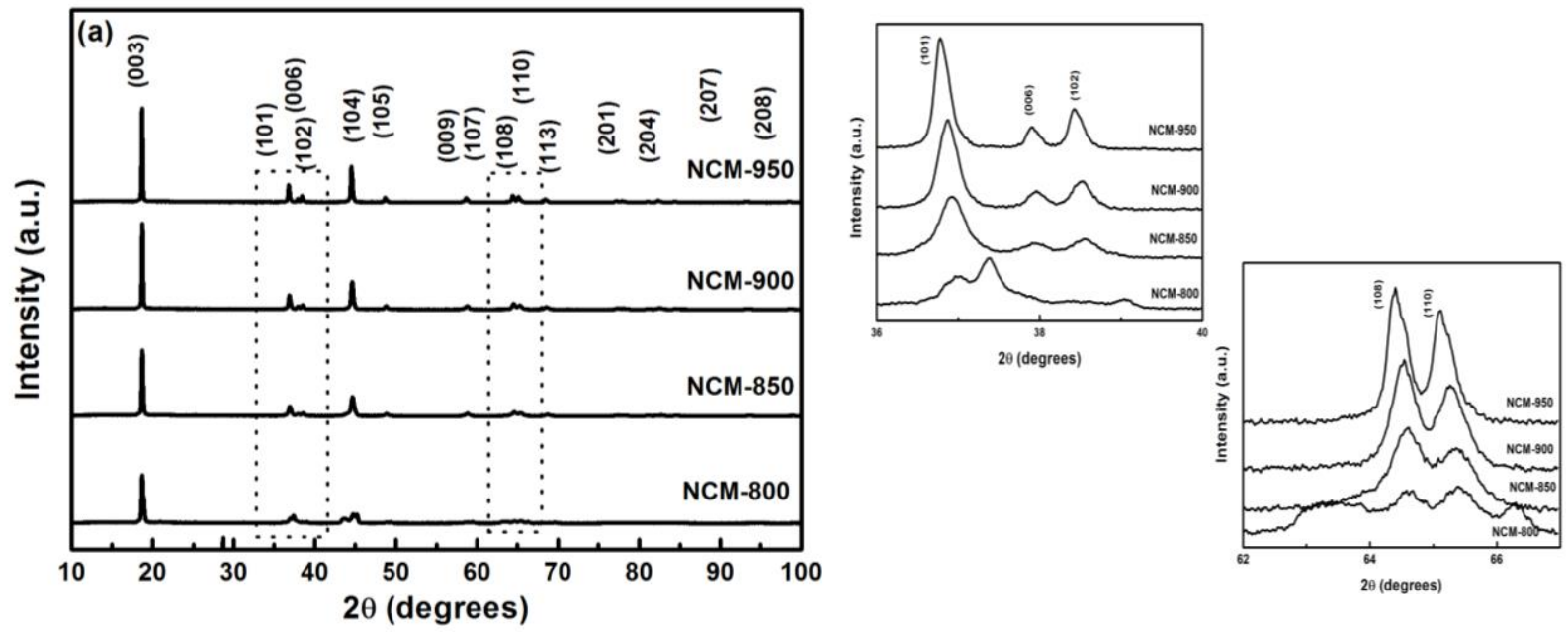

Figure 1. XRD patterns for synthesized materials.

TABLE I. Lattice parameters of the synthesized samples.

\begin{tabular}{cccccc}
\hline Sample & $\mathbf{a}(\boldsymbol{\AA})$ & $\mathbf{c}(\boldsymbol{\AA})$ & $\mathbf{V ~}(\mathbf{\AA} \mathbf{3})$ & $\mathbf{c} / \mathbf{a}$ & $\mathbf{R}$ \\
\hline NCM-800 & 2.8401 & 14.2426 & 99.489 & 5.0148 & 1.96 \\
NCM-850 & 2.8554 & 14.2350 & 100.516 & 4.9852 & 1.12 \\
NCM-900 & 2.8581 & 14.2312 & 100.679 & 4.9792 & 1.12 \\
NCM-950 & 2.8638 & 14.2494 & 101.214 & 4.9755 & 1.96 \\
\hline
\end{tabular}

In order to investigate the electrochemical performance, the cyclic voltammograms of NCM samples, with $1 \mathrm{M}$ and $1.5 \mathrm{M} \mathrm{LiPF}_{6}$ in the electrolyte, are presented in Fig. 2. As shown in this figure, for both concentrations, the $\mathrm{CV}$ peaks corresponding to a redox process can be seen better defined, at the range of $\sim 3.90-4.50 \mathrm{~V}$ corresponds to the redox couples of $\mathrm{Ni}^{3+} / \mathrm{Ni}^{4+}$ and $\mathrm{Co}^{3+} / \mathrm{Co}^{4+}$ and the other peak positioned at $>4.5 \mathrm{~V}$ is associated with the irreversible activation of $\mathrm{Li}_{2} \mathrm{MnO}_{3}$, along with the unavoidable formation of SEI film and the decomposition of electrolyte. The highest current associated with these peaks and a better reversibility related to the redox process is observed in NCM-850 electrode and this even clearer when $1.5 \mathrm{M}$ concentration of salt in electrolyte was used.

The potential gap value between oxidation and reduction peaks $(\Delta \mathrm{Ep})$ qualitatively describes the reversibility/polarization of the electrochemical process. As the cycling 
proceeds, the $\Delta \mathrm{Ep}$ shows a better reversibility for the NCM-850 electrode, in both concentrations.
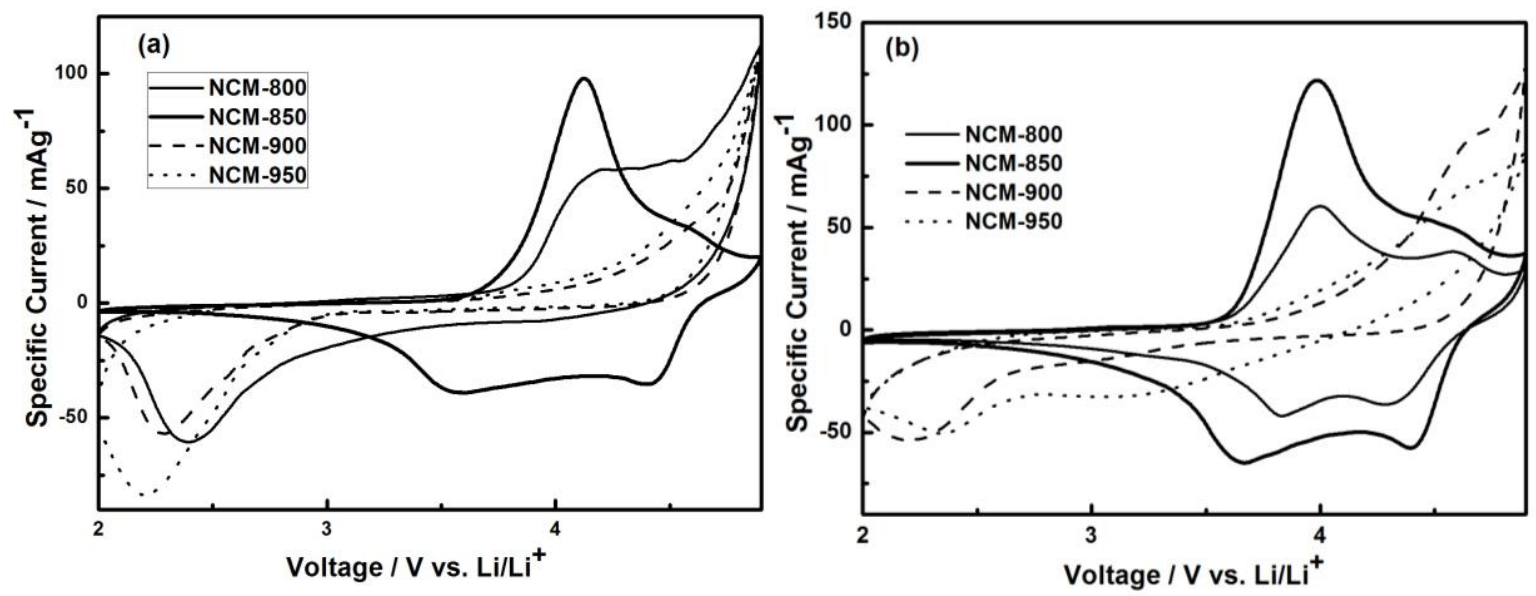

Figure 2. Cyclic voltammograms of NCM electrodes with a) $1 \mathrm{M} \mathrm{LiPF}_{6}$, and b) $1.5 \mathrm{M}$ $\mathrm{LiPF}_{6}$.

Cycle performance is the basic requirement to evaluate the cathode material's performance. The cycle performances of the working electrodes are displayed in Fig. 3. The initial charge capacities, with $1.0 \mathrm{M}$ of the concentration of salt in the electrolyte (Fig. 3 (a)), of NCM-800, NCM-850, NCM-900 and NCM-950 electrodes were 85, 148, 194 and $123 \mathrm{mAh} \mathrm{g}^{-1}$, respectively; and when $1.5 \mathrm{M}$ of the concentration of salt in the electrolyte was used (Fig. 3 (b) the initial charge capacities values of NCM-800, NCM-

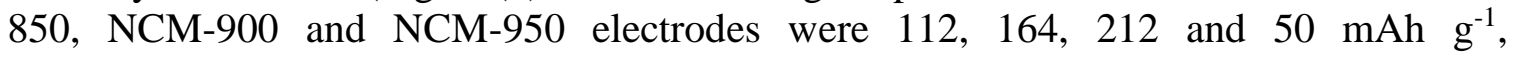
respectively. NCM-900 electrode exhibit the highest initial discharge specific capacities, however this decreases in cycling. The NCM-850 electrodes delivered a specific discharge capacity of $105 \mathrm{mAh} \mathrm{g}^{-1}$ and $127 \mathrm{mAh} \mathrm{g}^{-1}$ for the concentration of $1 \mathrm{M}$ and 1.5 $\mathrm{M} \mathrm{LiPF}_{6}$ respectively, after 75 cycles.
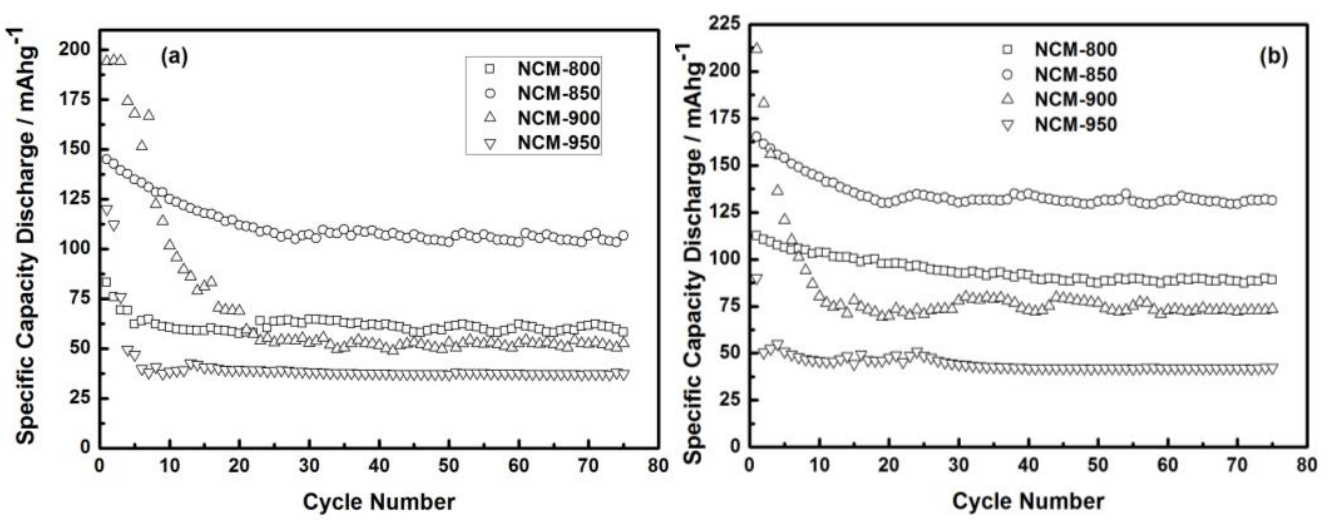

Figure 3. Cyclic performance of NCM electrodes with a) $1 \mathrm{M} \mathrm{LiPF}_{6}$, and b) $1.5 \mathrm{M} \mathrm{LiPF}$. 


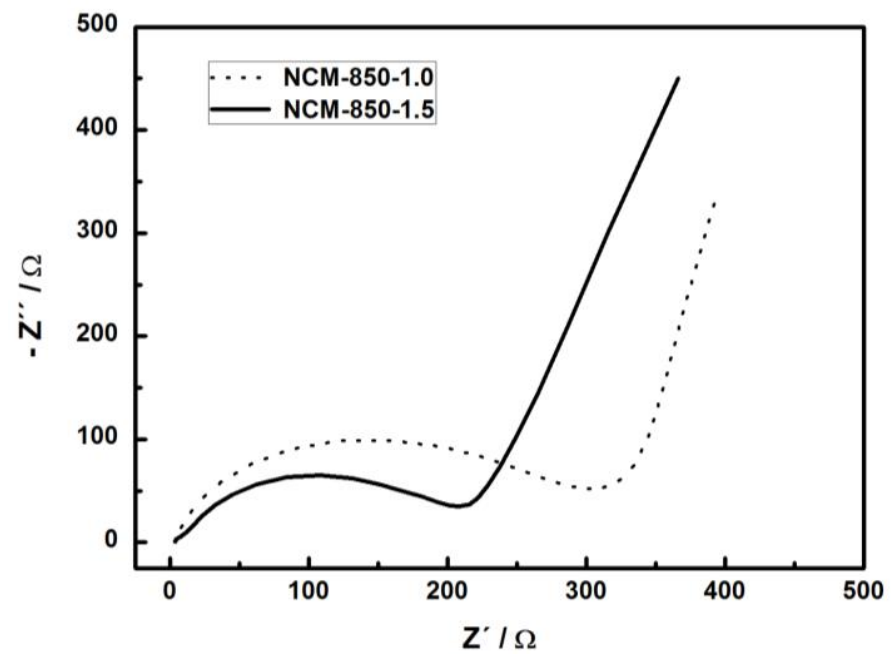

Figure 4. Nyquist's diagrams for NCM-850 electrode in $1 \mathrm{M}$ and $1.5 \mathrm{M}$ salt concentration of the electrolyte.

Nyquist diagrams at 50\% of charge, corresponding to NCM-850 working electrode, are presented in Fig. 4. In the high frequency domain, a distorted semicircle is observed, which can be associated with the overlapping of the SEI formation/ decomposition resistance along with the charge transfer process (resistance) in the cathode/electrolyte interface. In the low frequency region, a Warburg-type impedance was observed, that is related to the Li ion diffusion in the solid active material. The smaller high-frequency semicircle and lower higher impedance values observed in the impedance spectra of the NCM-850-1.5 electrode - it could be attributed to the resistive reaction layer.

\section{Conclusion}

In this paper the modification of the salt content in the electrolyte is proposed as an alternative to improve the electrochemical performance of NCM cathodes materials and for that, materials prepared at different temperatures are studied in two different salt concentrations, $1 \mathrm{M}$ and $1.5 \mathrm{M}$.

Results indicate that the NMC materials annealed at $850{ }^{\circ} \mathrm{C}(\mathrm{NCM}-850)$ exhibit an improvement of their electrochemical performance compared with that obtained with others temperatures, equally in concentrations $1 \mathrm{M}$ as $1.5 \mathrm{M}$. These improvements include better specific capacity and cycling stability. It should be noted that the use of $1.5 \mathrm{M}$ salt concentration has the best electrochemical behavior for these cathode materials, in which redox processes show a better reversibility and also deliver higher specific discharge capacity values, it could be attributed to lower polarization enhancement of reversibility for this redox reaction and growth of the resistive layer on the surface of the active material.

\section{Acknowledgments}

Authors gratefully acknowledge the financial support from the European Union, European Structural and Investment Funds Operational Program Research, Development 
and Education, and Ministry of Education, Youth and Sports of the Czech Republic under BUT specific research program (project $N^{\circ}$. CZ.02.2.69/0.0/0.0/16_027/0008371).

\section{References}

1. Q. Wanga, B. Mao, S. I. Stoliarov, J. Sun, Progress in Energy and Combustion Science, 73, 95 (2019).

2. A. Manthiram, ACS Cent. Sci., 3, 10, 1063 (2017).

3. A. Mishra, A. Mehta, S. Basu, S. J. Malode, N. P.Shetti, S. S. Shukla, M. N. Nadagouda, T. M. Aminabhavi, Materials Science for Energy Technologies, 1, 2, $182(2018)$.

4. E. K. Heidari, A. Kamyabi-Gol, M. H. Sohi, A. Ataie, J Ultrafine Grained Nanostruct Mater, 51(1), 1 (2018).

5. Q. Wang, L. Jiang, Y. Yu, J. Sun, Nano Energy, 55, 93 (2019).

6. Q. Li, J. Chen, L. Fan, X. Kong, Y. Lu, Green Energy \& Environment, 1, 18 (2016)

7. N. Nitta, F. Wu, J. T. Lee and G. Yushin, Materials Today, 18, 5, 252 (2015).

8. N. Bensalah and H. Dawood, J Material Sci Eng, 5, 4 (2016).

9. W. Lu, X. Guo, Y. Luo, Q. Li, R. Zhu, H. Pang, Chemical Engineering Journal, 355, 208 (2019).

10. M-J. Uddin, P. K. Alaboina, S-J. Cho, Materials Today Energy, 5, 138 (2017).

11. Y. Xi, Y. Liu, D. Zhang, S. Jin, R. Zhang, M. Jin, Solid State Ionics, 327, 27 (2018).

12. D. Liu, X. Fan, Z. Li, T. Liu, M. Sun, C. Qian, M Ling, Y. Liu, C. Liang, Nano Energy, 58, 786 (2019).

13. D. Zuo, G. Tian, X. Li, D. Chen, K. Shu, Journal of Alloys and Compounds, 706, 24 (2017).

14. X.B. Zheng, X.H. Li, Z.J. Huang, B. Zhang, Z.X. Wang, H.J. Guo, Z.H. Yang, J. Alloys Compd., 644, 607 (2015).

15. X. Li, X. Zhao, M.S. Wang, K.J. Zhang, Y. Huang, M.Z. Qu, Z.L. Yu, D.S. Geng, W.G. Zhao, J.M. Zheng, RSC Adv., 7, 24359 (2017).

16. H. Chen, Q. Hu, Z. Huang, Z. He, Z. Wang, H. Guo, X. Li, Ceram. Int., 42, 263 (2016). 